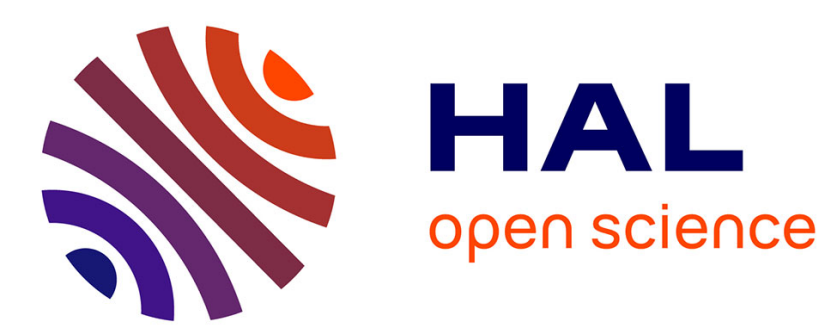

\title{
Modelling the Structure and Vibrational Properties of Layered Double Hydroxides
}

\author{
Erwan André, Jean Fahel, Cédric Carteret
}

\section{To cite this version:}

Erwan André, Jean Fahel, Cédric Carteret. Modelling the Structure and Vibrational Properties of Layered Double Hydroxides. Energy Technology 2015: Carbon Dioxide Management and Other Technologies, Mar 2015, Orlando, United States. 10.1002/9781119093220.ch35 . hal-01511737

\section{HAL Id: hal-01511737 \\ https://hal.univ-lorraine.fr/hal-01511737}

Submitted on 22 May 2018

HAL is a multi-disciplinary open access archive for the deposit and dissemination of scientific research documents, whether they are published or not. The documents may come from teaching and research institutions in France or abroad, or from public or private research centers.
L'archive ouverte pluridisciplinaire HAL, est destinée au dépôt et à la diffusion de documents scientifiques de niveau recherche, publiés ou non, émanant des établissements d'enseignement et de recherche français ou étrangers, des laboratoires publics ou privés. 


\title{
MODELLING THE STRUCTURE AND VIBRATIONAL PROPERTIES OF LAYERED DOUBLE HYDROXIDES
}

\author{
Erwan Andre, Jean Fahel, Cedric Carteret
}

Laboratoire de Chimie Physique et Microbiologie pour l'Environnement (LCPME) UMR7564

CNRS - Lorraine University; 405 rue de Vandoeuvre; Villers-lès-Nancy, 54602, France

Keywords: Layered Double Hydroxides, DFT, Infra-Red, Raman, XRD

\begin{abstract}
A model structure is proposed for the layered double hydroxide $\left[\mathrm{Mg}_{2} \mathrm{Al}(\mathrm{OH})_{6}\right]^{+} \cdot \mathrm{Cl}^{-}(\mathrm{Mg} / \mathrm{Al}$ ratio $R=2$ ). The structural parameters of this model have been optimized by DFT calculations and both PXRD and vibrational spectra have been simulated. The comparison with experimental data confirms the validity of the model. Thanks to the synergy between experiment and theory it is now possible to analyze in detail the vibrational signals and understand the interactions between the different components of this material.
\end{abstract}

\section{Introduction}

Layered Double Hydroxides (LDHs) also known as anionic clays are well known for their proprieties of anion exchanger, pollutant scavenger, or catalyst precursors [1,2]. They can be represented by their general formula $\left[\mathrm{M}^{\mathrm{II}}{ }_{(1-\mathrm{x})} \mathrm{M}^{\mathrm{III}}{ }_{\mathrm{x}}(\mathrm{OH})_{2}\right]^{\mathrm{x}+}\left[\mathrm{A}^{\mathrm{n}-}{ }_{\mathrm{x} / \mathrm{n}}, \mathrm{z} \mathrm{H}_{2} \mathrm{O}\right]^{\mathrm{x}-}$.In this formula, one can see the different factors which rule the composition of this material: MII and MIII form a couple of divalent and trivalent cations constituting sheets of face sharing hydroxyl octahedra, An- is a charge balancing anion, $\mathrm{x}$ is the layer charge and $\mathrm{z}$ is the amount of intercalated water molecules. One can also define $\mathrm{R}=(\mathrm{x}-1) / \mathrm{x}$ which is the $\mathrm{M}^{\mathrm{II}} / \mathrm{M}^{\mathrm{III}}$ ratio. LDHs form a complex system in which different factors such as: The layers composition, the stacking sequence or the structuration of the interlayer domain can influence their properties of anion exchanger or nanoreactor [3].

If the X-Ray Diffraction (XDR) is the technique of choice to characterize the structure of these materials at the crystal scale (stacking sequence, interlayer spacing...) through vibrational spectroscopy (Infra-Red and Raman) it is possible to access in situ information, at molecular scale, of both anionic and cationic parts of these systems.

The aim of this work is to show how quantum mechanical simulations (realized at DFT level through a periodic approach) can rely on experimental data brought by XRD and vibrational spectroscopies to validate a model structure. And in return, how computed data obtained from this model can help to assign the experimental signatures of LDHs as well as they give access to various properties depending on the electronic distribution.

To illustrate this methodology, a focus is made on the compound $\left[\mathrm{Mg}_{2} \mathrm{Al}(\mathrm{OH})_{6}\right]^{+} \cdot \mathrm{Cl}^{-}$(named HTC hereafter), that possess the same layer structure as Hydrotalcite (natural mineral) but a different intercalated anion $\left(\mathrm{CO}_{3}{ }^{2-}\right)$. This choice is motivated by the fact that chloride is an atom and thus does not possess any vibrational signature, making this compound the simplest system that can be modelled.

Experimental details 


\section{$\underline{\text { Sample preparation }}$}

The synthesis of the carbonate LDH precursor was performed through the method of precipitation at low supersaturation [4]. Typically, a $0.4 \mathrm{M}$ solution of $\mathrm{MgCl}_{2}$ and $\mathrm{AlCl}_{3}$ salts with $\mathrm{R}=2$ was added slowly $(0.3 \mathrm{~mL} / \mathrm{min})$ to an anionic solution of $\mathrm{Na}_{2} \mathrm{CO}_{3}(0.25 \mathrm{M})$. The $\mathrm{pH}$ was kept constant at 11 by simultaneous addition of $\mathrm{NaOH}(1 \mathrm{M})$ solution using an automatic titrator device. After complete addition of the cationic solution, the slurry was then placed in autoclave and heated at $100^{\circ} \mathrm{C}$ for $20 \mathrm{~h}$. The final solid was washed several times with deionized water and dried in oven at $60^{\circ} \mathrm{C}$ over a night.

The conversion of the carbonate precursor to the chloride LDH was performed using the method proposed by Iyi [5]. An ethanolic solution prepared by diluting a $1 \mathrm{M} \mathrm{HCl}$ solution in $5 \mathrm{~mL}$ of ethanol was slowly added to a vigorously stirred $\mathrm{CO}_{3}{ }^{2-} \mathrm{LDH}$ solution $(0.662 \mathrm{mmol})$ in $45 \mathrm{~mL}$ ethanol solution under Argon flow. The factor f, defined by Iyi et al. as $\mathrm{f}=[\mathrm{HX}] /\left(2 *\left[\mathrm{CO}_{3}{ }^{2-}\right]\right)$ where $[\mathrm{HX}]$ represents the monoprotic acid concentration, was set to 1.5. The solution was stirred for 1 hour at room temperature under Argon flow. Then, the resulting suspension was filtered with a polycarbonate membrane with $0.2 \mu \mathrm{m}$ pore size, washed thoroughly with absolute ethanol and dried in oven at $60^{\circ} \mathrm{C}$.

\section{Characterization}

The ratio $\mathrm{R}$, as well as the chloride content of both precursor and exchanged LDH was determined by Inductively Coupled Plasma equipped with atomic emission spectrometry detection (ICP-AES).

Infrared measurements, recorded in the range $4000-400 \mathrm{~cm}^{-1}$ on a Nicolet 8700 apparatus continuously purged with ultrapure $\mathrm{N}_{2}$, were carried out with a DTGS- $\mathrm{KBr}$ detector and a $\mathrm{KBr}$ beam splitter. The spectral resolution was $4 \mathrm{~cm}^{-1}$ and 100 scans were co-added for each spectrum. Samples were pellets made of a ground mixture of dried $\mathrm{KBr}$ (FTIR grade) and $1 \%$ weight of $\mathrm{LDH}$ powder pressed up to 5 tons. A pure $\mathrm{KBr}$ pellet was used as background. In the range $650-80 \mathrm{~cm}^{-1}$, spectra were acquired with a DTGS-PE detector and a solid substrate beam splitter. Samples were prepared by depositing $170 \mu \mathrm{L}$ of a $4 \mathrm{~g} / \mathrm{L}$ LDH suspension on a $13 \mathrm{~mm}$ polyethylene (PE) pellet diameter. All suspensions were prepared with deionized water to avoid carbonate contamination of Cl-LDH samples. A pure PE pellet was used as background. For background and samples, two spectra were averaged to minimize random noise.

Raman spectra were obtained using the Argon laser excitation line at $514.5 \mathrm{~nm}$ of a Jobin-Yvon T64000 spectrometer equipped with a liquid nitrogen cooled Charged-Coupled device (CCD). The power of the excitation source was set to $200 \mathrm{~mW}$. The scattered light was collected in a backscattering configuration by a microscope using an X50 olympus objective (laser spot $\sim 4$ $\mu \mathrm{m})$. The instrumental resolution was $\sim 4 \mathrm{~cm}^{-1}$.

X-ray diffraction patterns were recorded with a Phillips X'Pert Pro MPD diffractometer in reflection geometry using $\mathrm{Cu} \mathrm{K}_{\alpha 1}$ radiation $(\lambda=154,06 \mathrm{pm})$. Data were collected with a dedicated chamber from finely ground samples. The $2 \theta$ range was explored between 5 and $100^{\circ}$ at a speed of $2 \% \mathrm{~min}$.

\section{Computational details}

Calculations were performed with the CRYSTAL14 periodic ab initio code [6,7], by using an all-electron Gaussian type basis set and various functionals. Most of the results will refer to the hybrid B3LYP functional [8,9], that has been shown to provide excellent results for the vibrational properties of ionic and semi-ionic compounds [10], but slightly overestimated 
distances and cell volumes. To overcome this issue a B3LYP-D* scheme have been adopted, where the hybrid B3LYP functional is coupled to a Grimme approach [11,12] with parameters specifically optimized for the solid state [13]; this permits to take into account dispersive forces, that are expected to play an important role in determining the equilibrium structure of the present systems. Magnesium, aluminum, chlorine, oxygen and hydrogen were described by (8s)-(511sp)(1d), (8s)-(621sp)-(1d), (8s)-(6311sp)-(1d),(8s)-(411sp)-(1d) and (211s)-(1p) contractions, respectively. The level of accuracy in evaluating the Coulomb and Hartree-Fock exchange series is controlled by five parameters [7], for which the 777818 values were used. The threshold on the SCF energy was set to $10^{-10} \mathrm{Ha}$ for both the geometry optimization and the frequency calculation. The reciprocal space was sampled according to a sublattice with shrinking factor set to 4 (along the 3 lattice vectors), corresponding to 24 and 36 independent $\mathrm{k}$ vectors in the irreducible part of the Brillouin zone.

\section{Construction and validation of the model}

In order to model the vibrational signature of LDHs, the first step is to construct a proper model of its crystalline structure. LDHs possess the same layer structure as Brucite $\mathrm{Mg}(\mathrm{OH})_{2}$ that crystallizes in P-3m1 space group (sequential number $\mathrm{n}^{\circ}: 164$ ) with $\mathrm{Mg}$ in site $1 \mathrm{a}$ and $\mathrm{OH}$ in site 2d (Wyckoff positions) [14]. In the case of HTC, the metal position can be occupied either by $\mathrm{Mg}$ or $\mathrm{Al}$ with a global ratio of $\mathrm{R}(\mathrm{Mg} / \mathrm{Al})=2$. But periodic quantum calculations do not support partial occupations. One has to define a supercell to describe the cation distribution. In the case of a ratio $\mathrm{R}(\mathrm{Mg} / \mathrm{Al})=2$ there is only one way to distribute the cations in order to avoid two consecutive $\mathrm{Al}(\mathrm{OH})_{6}$ octahedra. This distribution can be described with a hexagonal supercell of $\mathrm{a} \sqrt{3}$ length [15] as displayed in figure 1.

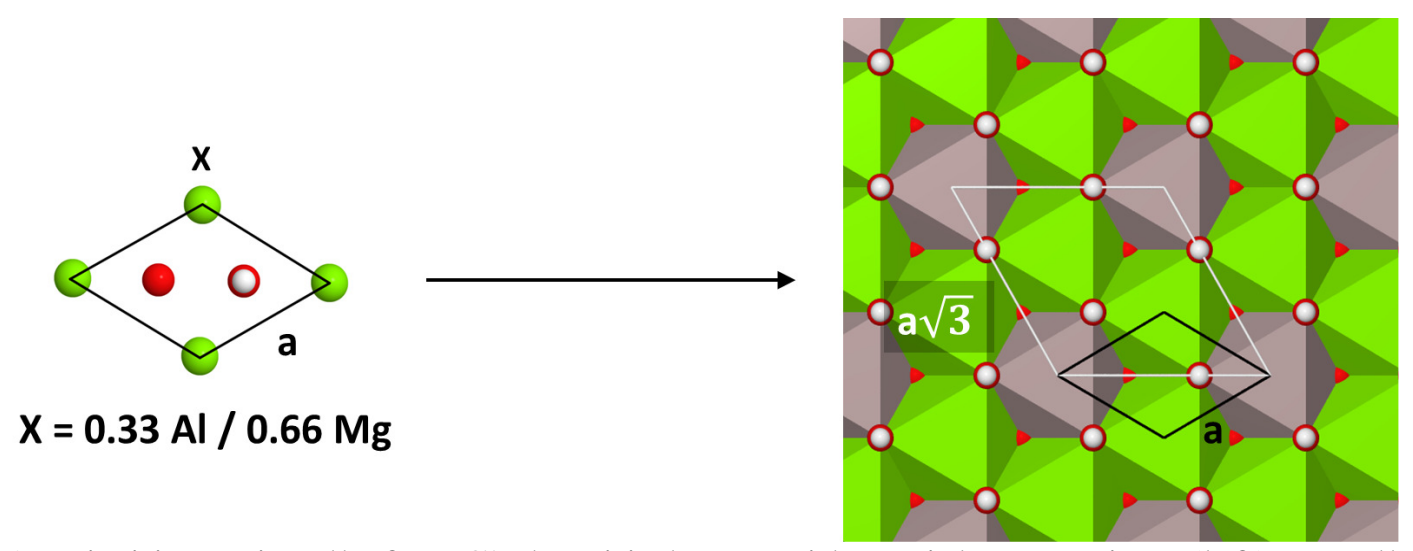

Figure 1: Primitive unit cell of HTC's brucitic layers with partial occupations (left) as well as the corresponding supercell used in calculations (right). Mg octahedra are green, Al octahedral are purple.

Depending on the way the layers stack, different polytypes can be formed [16]. The relative position of the layers hydroxides defines two types of crystallographic sites for the anion insertion: Octahedral or Prismatic. The nature of the preferred site (and thus polytype) depends on the interlayer content. One can cite the nature of the intercalated anion and its way to interact with the layer (hydrogen bonding versus electrostatic interaction) or the water content of the interlayer domain. All the stacking possibilities up to three layers have been tested. After optimization of their structures, the energy differences between the different models (a few kcal.mol ${ }^{-1}$ ) were too small to draw a firm conclusion. To be able to go further, theoretical results had to be compared with experimental data. As powder X-Ray Diffraction (PXRD) is the technic 
of choice regarding the structure determination of $\mathrm{LDH}$, this technic has been chosen to discriminate the different models. The PXRD patterns have been constructed using the theoretical structure factors obtained from the optimized structures. The patterns of the two most stable structures are compared to experimental data in figure 2.

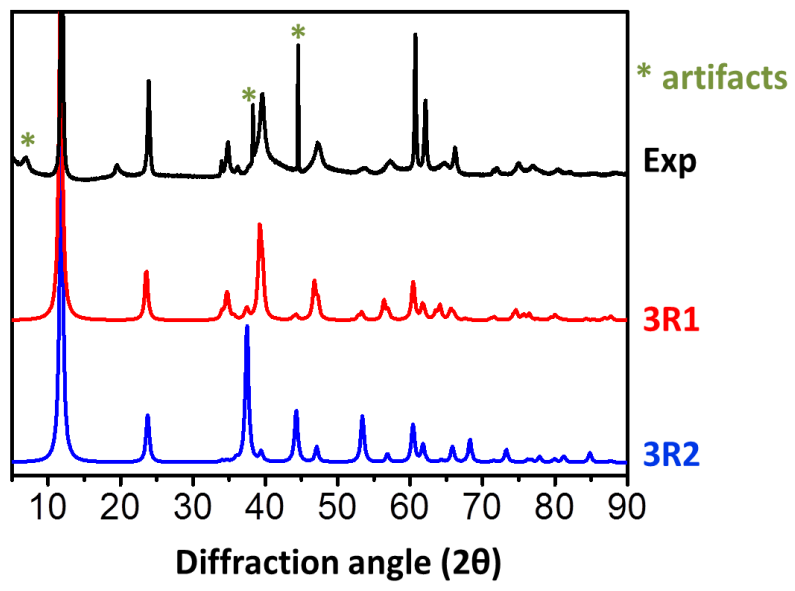

Figure 2: Comparison between experimental powder diffraction pattern of HTC and simulated patterns corresponding to $3 \mathrm{R} 1$ and $3 \mathrm{R} 2$ polytypes.

While the theoretical patterns are similar for low angles (corresponding to interlayer distance) they differ in the $30-55^{\circ}(2 \theta)$ region, which is characteristic of the stacking sequence. One can clearly see that in that case, the $3 \mathrm{R} 1$ polytype fit better the experimental pattern. This stacking sequence can be described with an orthorhombic cell of R-3m symmetry (sequential number $n^{\circ}$ : 166) containing three layers However, for the sake of computational time, the size of the system has been reduced by considering a monoclinic cell of $\mathrm{Cm}$ symmetry that contain only one layer. In order to ease the comparison with experiment data, the crystallographic information displayed Table 1 are expressed in the orthorhombic cell.

\begin{tabular}{|l|rr|}
\hline HTC & Experiment & Theory \\
\hline $\mathrm{a}$ & 3.048 & 3.048 \\
$\mathrm{c}$ & 22.314 & 22.410 \\
$\alpha$ & 90.0 & 89.2 \\
$\mathrm{~V}$ & 120.0 & 119.9 \\
$\mathrm{~V}$ & 179.5 & 180.4 \\
$\mathrm{Cz}$ & 7.438 & 7.469 \\
\hline
\end{tabular}

Table 1: Calculated and experimental (XRD) in R-3m symmetry cell parameters (lengths $[\AA]$, angles $\left.\left[{ }^{\circ}\right]\right)$ and cell volume $\mathrm{V}\left[\AA^{3}\right] . \mathrm{Cz}$ is the interlayer spacing.

As it appeared in the XRD patterns, the agreement between theory and experiment is fairly good. The interlayer is slightly overestimated and, due to the symmetry lowering, the angles are distorted in the monoclinic structure although remaining very close to ideal values. These results confirm the validity of the current model. It is now possible to study its vibrational signature.

\section{Vibrational spectra}

The vibrational frequencies of the HTC's crystal have been calculated within the harmonic approximation at the $\Gamma$ point. The computation of the dipole moment derivative gives access to 
Infra-Red intensities. It is then possible to reconstruct a theoretical IR spectrum and to compare it to experimental data as shown in figure 2. Likewise, Raman intensities can be calculated from the third derivative of the total energy (twice with respect to an externally applied electric field and once with respect to the atomic displacements) and a theoretical spectrum can be constructed. Those theoretical spectra are compared to experimental data in figure 3.

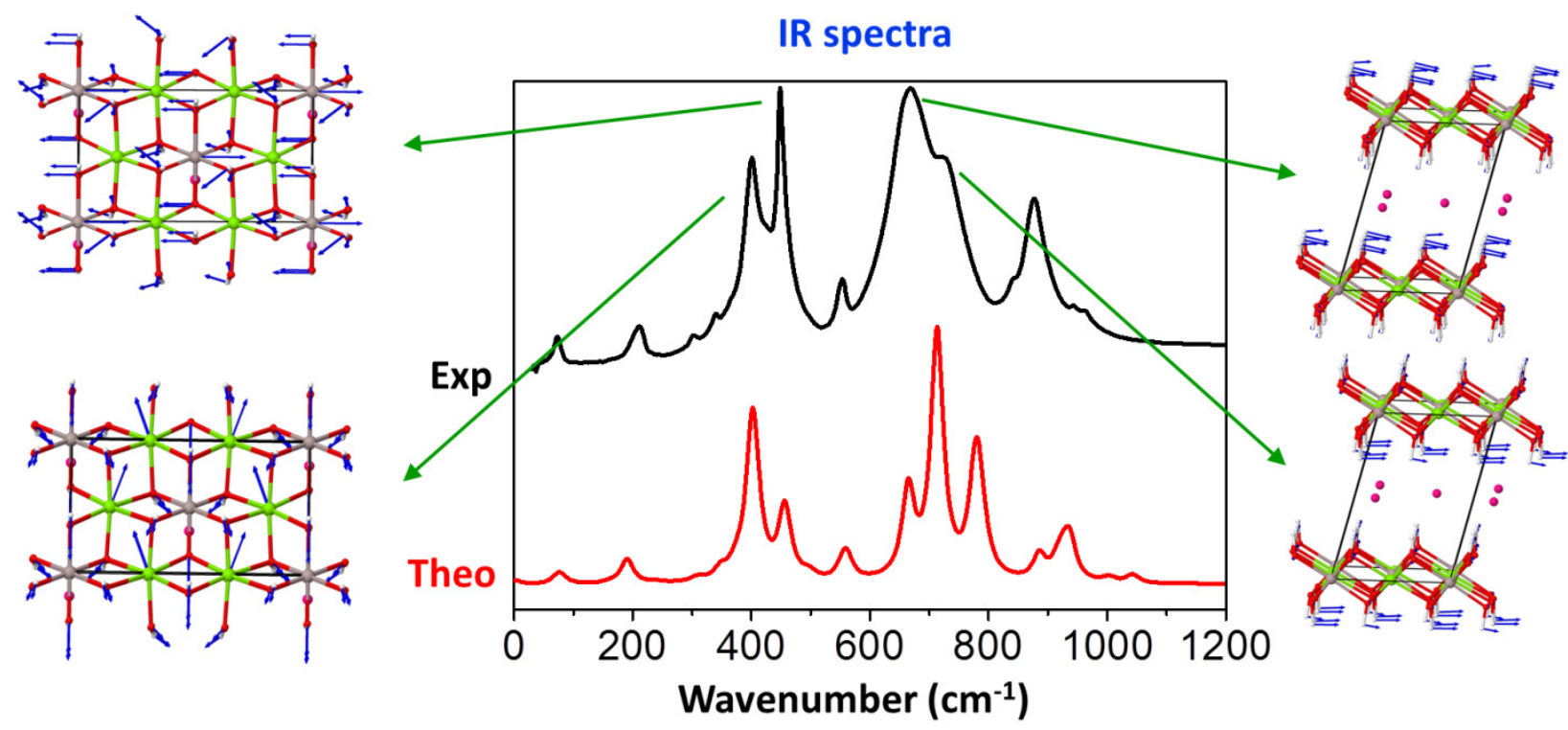

Figure 2: Comparison between experimental and simulated IR spectra of HTC. The normal vibration modes of the main pics are also displayed.

The Infra-Red spectrum of HTC is characterized by two main groups of pics. One around 400 $\mathrm{cm}^{-1}$ and the second around $700 \mathrm{~cm}^{-1}$. Each one of these pics can be assigned in the theoretical spectrum to its corresponding normal mode. For example, the two most intense pics in the first group correspond to deformations of the layer's octahedra. One can see clearly that the contributions of the divalent and trivalent cations are decoupled. The pic at low frequency expresses the contribution of the magnesium's framework while the one at $450 \mathrm{~cm}^{-1}$ correspond to the deformation of the aluminum's octahedra. One can note that even if the model reproduces correctly the positions of the pics, the modelling of intensities is less good as the relative intensities of these two modes is reversed. The second group of pics can be assigned to layers hydroxides bending modes. The splitting of these modes is due to differences of chemical environment of between those hydroxides. Indeed, the shift in layer stacking defined by the polytype, imposes that hydroxides interacting with the chloride anion are not the same in the "upper" layer than those of the "lower" layer.

The figure of the Raman spectra illustrate a limitation of the modeling process: The width of the different pics is not computed. To draw a spectrum a constant value is given to all the pics. The consequence is that the width of some pics is strongly underestimated. It can be seen for the pics around $700 \mathrm{~cm}^{-1}$ in the theoretical Raman spectrum. This is due to the high anharmonicity of these vibrations. A more realistic model for the width would require computing the coupling between each mode and all the others that is not possible in the current version of the crystal code. 


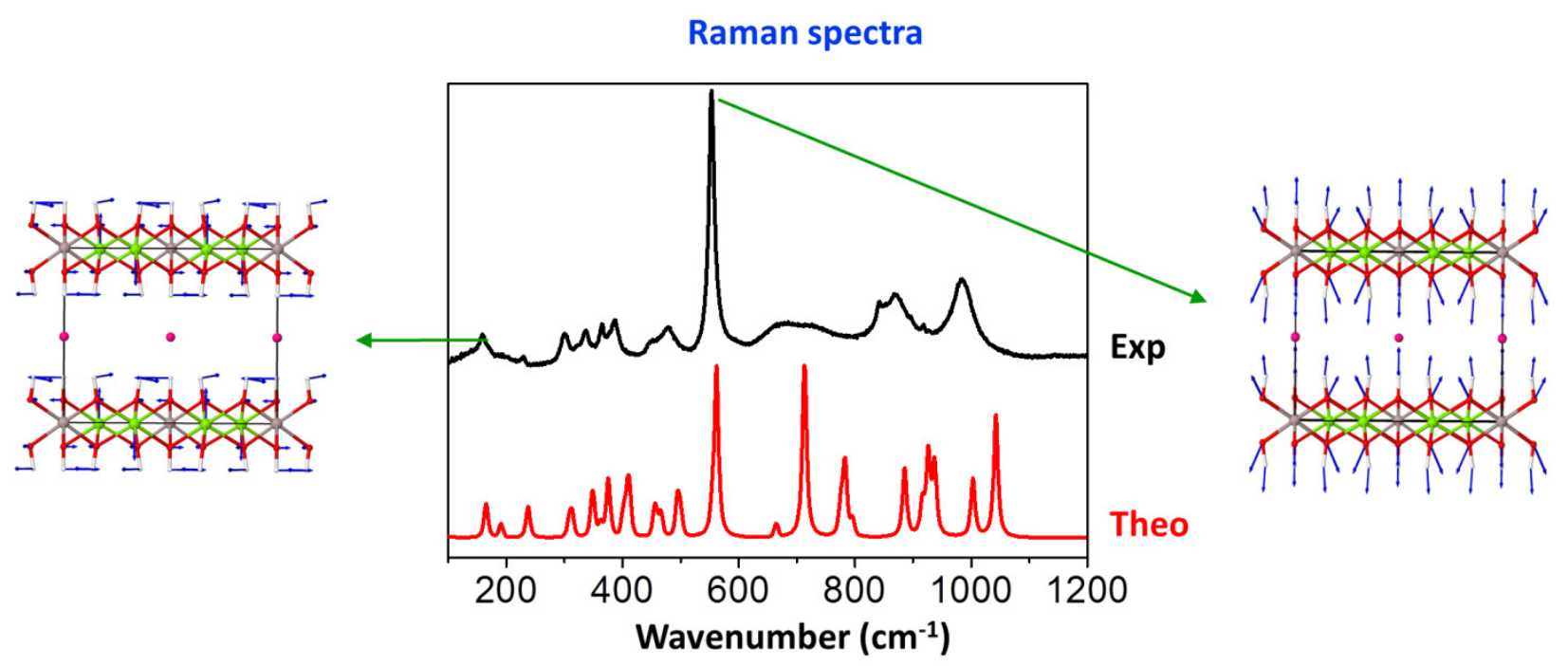

Figure 3: Comparison between experimental and simulated Raman spectra of HTC along with vibration modes of characteristic pics.

The main pic in the Raman spectrum of HTC corresponds to the symmetric elongation of the M$\mathrm{OH}$ distances (breathing) of the octahedral layers. As it is easier to record to access to low frequencies with the Raman spectroscopy, we can highlight the pic at $160 \mathrm{~cm}^{-1}$. It corresponds to an out of layer's plane motion of the magnesium atoms.

\section{Conclusion}

A model structure has been constructed for the $\mathrm{LDH}\left[\mathrm{Mg}_{2} \mathrm{Al}(\mathrm{OH})_{6}\right]^{+} \cdot \mathrm{Cl}^{-}$. The validity of this model, including the stacking sequence, has been confirmed by the comparison to experimental XRD powder pattern. Using this model, it is possible to simulate the vibrational spectra and to compare with experimental Infra-Red and Raman data. The comparison between theoretical spectra and experimental ones serves two different goals: First, it is possible to detect in the experimental spectrum any signal that does not correspond to the model (amorphous phases, impurities...). But more important: thanks to the theoretical spectrum, it is possible to assign each pic to its corresponding normal mode. Then, it becomes easier afterwards to explain the evolution of the measured signals when a perturbation is applied to the material (hydration, anion exchange...).

\section{References}

1. V. Rives, Layered Double Hydroxides: Present and Future (Nova Publishers, 2001).

2. X. Duan and D. G. Evans, Layered Double Hydroxides (Springer Science \& Business Media, 2006).

3. G. R. Williams and D. O'Hare, J. Mater. Chem. 16, 3065 (2006).

4. B. Grégoire, C. Ruby, and C. Carteret, Cryst. Growth Des. 12, 4324 (2012).

5. N. Iyi, H. Yamada, and T. Sasaki, Appl. Clay Sci. 54, 132 (2011).

6. R. Dovesi, R. Orlando, A. Erba, C. M. Zicovich-Wilson, B. Civalleri, S. Casassa, L. Maschio, M. Ferrabone, M. De La Pierre, P. D’Arco, Y. Noël, M. Causà, M. Rérat, and B. Kirtman, Int. J. Quantum Chem. 114, 1287 (2014). 
7. R. Dovesi, V. R. Saunders, C. Roetti, R. Orlando, C. M. Zicovich-Wilson, F. Pascale, B. Civalleri, K. Doll, N. M. Harrison, P. D’Arco, M. Llunell, M. Causà, and Y. Noël, CRYSTAL14 User's Manual (2014).

8. A. D. Becke, J. Chem. Phys. 98, 5648 (1993).

9. C. Lee, W. Yang, and R. G. Parr, Phys. Rev. B 37, 785 (1988).

10. M. De La Pierre, C. Carteret, L. Maschio, E. André, R. Orlando, and R. Dovesi, J. Chem.

Phys. 140, 164509 (2014).

11. S. Grimme, J. Comput. Chem. 25, 1463 (2004).

12. S. Grimme, J. Comput. Chem. 27, 1787 (2006).

13. P. Ugliengo, C. M. Zicovich-Wilson, S. Tosoni, and B. Civalleri, J. Mater. Chem. 19, 2564 (2009).

14. T. Nagai, T. Hattori, and T. Yamanaka, Am. Mineral. 85, 760 (2000).

15. D. G. Costa, A. B. Rocha, R. Diniz, W. F. Souza, S. S. X. Chiaro, and A. A. Leitão, J. Phys. Chem. C 114, 14133 (2010).

16. A. S. Bookin and V. A. Drits, Clays Clay Miner. 41, 551 (1993). 